\title{
A role for seminal plasma in modulating pregnancy outcomes in domestic species
}

\author{
John J Bromfield \\ D H Barron Reproductive and Perinatal Biology Research Program, Department of Animal Sciences, \\ University of Florida, Gainesville, Florida, USA \\ Correspondence should be addressed to J J Bromfield; Email: jbromfield@ufl.edu
}

\begin{abstract}
Seminal plasma is a complex fluid produced by the accessory glands of the male reproductive tract. Seminal plasma acts primarily as a transport medium for sperm on its arduous journey through the male and then female reproductive tract following ejaculation. This spermatozoan expedition will hopefully result in the meeting of and resultant fertilization of an oocyte, perpetuating the genetic lineage of both sexes. Whereas seminal plasma has historically been perceived as only a transport medium providing a nutrient-rich fluid environment for sperm during this exchange of genetic material, new insights into a complex communication pathway between males and females has been unraveled in the past 30 years. This new research suggests seminal plasma as a method to promote early pregnancy success by modulating cellular and molecular adaptions of the maternal environment required to facilitate healthy, successful pregnancy outcomes. Whereas much work on this exciting new communication process has focused on mice and translation to human reproduction, here we review the current evidence in domestic species where artificial insemination in the absence of seminal plasma is routine. Improving artificial insemination in domestic species to optimize offspring health and productivity could have far-reaching impacts on agriculturally relevant species such as cattle, sheep, pigs and horses.

Reproduction (2016) 152 R223-R232
\end{abstract}

\section{Introduction}

Transport of sperm through the reproductive tract of males and then females is key to the functional role of seminal plasma (SP). The molecular makeup of $\mathrm{SP}$ is complex and species specific. SP is comprised of energy substrates for sperm in the form of simple sugars, antioxidant agents to prevent potential sperm DNA damage, minerals and salts, and a large number of diverse protein moieties of unknown function. It is now postulated that a role for some of these SP proteins is direct communication with the female reproductive tract to alter uterine function and drive physiological changes to the maternal milieu that increase pregnancy success and promote healthy outcomes for potential offspring (summarized in Fig. 1). Whereas much of this groundbreaking work has been performed elegantly in rodents for reasons pertaining to model accessibility and translation to human health, the question remains whether the communication pathway between males and females via SP exist in livestock species. It has been demonstrated that such communication exists between males and females of the insect world where postmating SP exposure in crickets, mosquitos and flies can elicit behavioral and physiological changes in females pertaining to reproductive outcomes (reviewed in Avila et al. (2011)). However, in domestic species where artificial insemination (AI) in the absence (or significantly reduced presence) of SP is sometimes more prevalent than natural conception, we do not know the full extent of SP's actions on the female reproductive tract or pregnancy outcomes. It is also important to note the anatomical and physiological differences in reproduction among domestic species, such as ruminants where embryo implantation occurs much later and placentation is less invasive than the mouse or human where these processes share greater anatomical and temporal similarities. This review will focus on the newer paradigm of SP acting beyond a transport medium for sperm and as an agent that may optimize pregnancy outcomes in mammals.

\section{What is the role of SP in modulating reproduction in the mouse and human?}

Much of the cutting-edge investigations into the role $\mathrm{SP}$ plays in modulating the maternal environment have been performed in rodents and humans. These studies have broadened our basic understanding of biology and have been approached to impact human reproductive health. However, when interpreting 

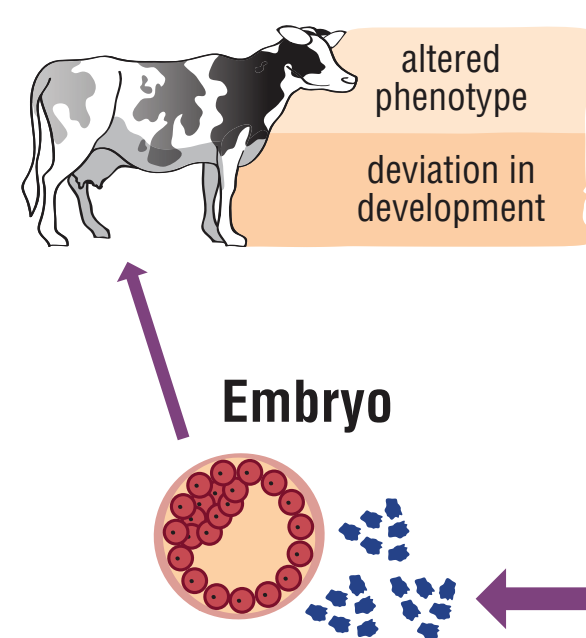

Embryokines
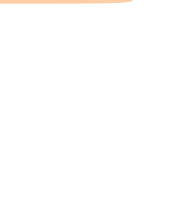

\section{Semen}

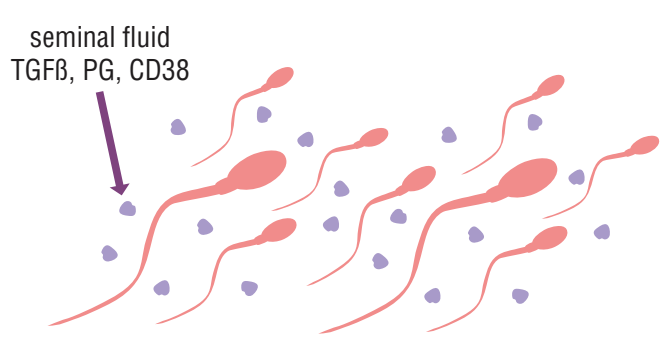

Lumen
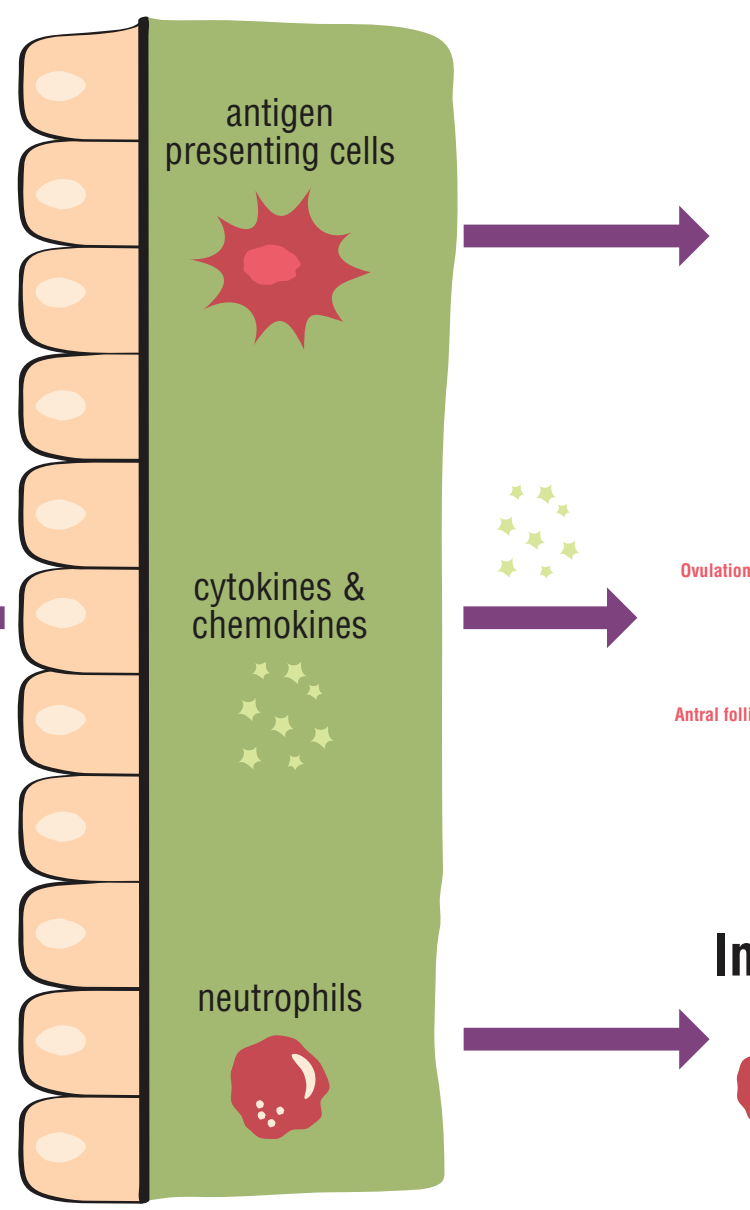

Immune tolerance
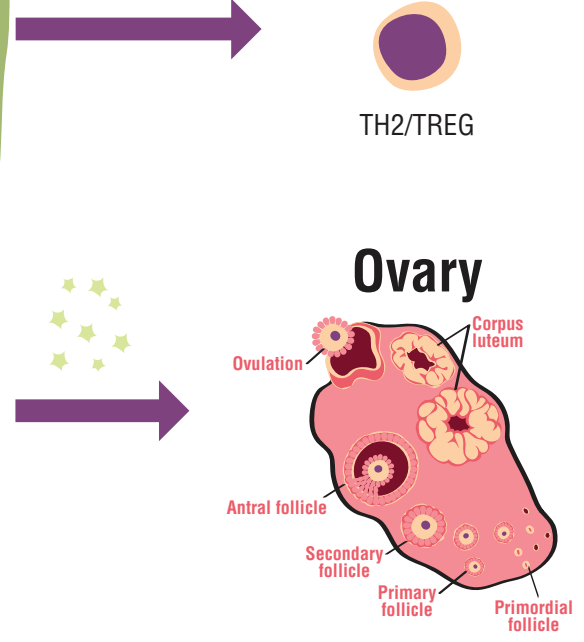

Endometrium

Figure 1 Schematic representation of the proposed impact of seminal plasma on the maternal environment. This figure represents the allencompassing impact of seminal plasma on endometrial inflammation, production of embryokines and modulation of the maternal immune response to pregnancy and the ovary. We propose that these modulations in combination can effect embryo growth, pregnancy success and potentially the health and productivity of offspring. Inflammation; factors in seminal plasma induce expression of endometrial cytokines and chemokines in turn recruiting inflammatory cells and driving tissue remodeling. Embryo; the embryo is positively affected by the secretion of embryokines in the oviduct and uterus in response to seminal plasma exposure. Immune tolerance; insemination increases hypertrophy in the draining lymph nodes of the uterus, seminal plasma in turn increases proliferation of T-regulatory cells reactive toward paternal antigens expressed in semen, while a systemic skewing of the maternal immune system is directed to a beneficial Th2 profile. Ovary; seminal plasma exposure increases inflammation in the ovary following insemination and alters corpus luteum growth and progesterone production. All of these effects in combination culminate by improving pregnancy outcomes and optimizing the health and efficiency of offspring. Illustration by Tracy Bryant, UF/IFAS.

studies performed in the mouse, while undoubtedly valuable, caution must be applied when extrapolating to humans or domestic species. Research has demonstrated that murine models of inflammation are considerably divergent between mice and humans (Seok et al. 2013). Moreover, the reproductive physiology of ruminants is considerably different from mice with very different forms of placentation and temporal embryonic development and implantation. Many domestic species have noninvasive, or semi-invasive placental types where a priming of the maternal immune system with paternal antigen may not be as beneficial as in hemochorial placental mammals.

\section{$S P$-induced inflammation and immune modulation in maternal tissues}

Following insemination in both rodents and humans an acute inflammatory reaction is observed in the endometrium and cervix (Robertson et al. 1996, Sharkey et al. 2012b). It is believed that this acute inflammatory response which results in the recruitment of leukocytes including neutrophils, macrophages and dendritic cells to the endometrium and cervix is to facilitate clearance of debris and pathogens introduced during coitus, sperm selection and most intriguingly induction of immune tolerance to paternal antigens potentially expressed on the resultant semi-allogeneic conceptus. Post-insemination inflammation is not 
evident in mice mated to males replete of SP following surgical removal of the seminal vesicle glands or in women following condom-protected intercourse, suggesting that the initiating factor(s) for the observed inflammation is contained within SP (Robertson et al. 1996, Sharkey et al. 2012b). Indeed, in vitro studies using both rodent and human semen have been able to demonstrate that the cytokine transforming growth factor beta (TGF $\beta$ ) is the key modulating factor in SP to result in post-insemination maternal inflammation (Tremellen et al. 1998, Gutsche et al. 2003, Sharkey et al. 2012a). A major role of SP-derived TGF $\beta$ is to induce the expression of proinflammatory cytokines by the endometrium or cervix and initiate the postinsemination recruitment of inflammatory immune cells (reviewed in Robertson (2005)). New evidence suggests that the innate immune system is also involved with post-insemination inflammation. The importance of toll-like receptor (TLR) 4 signaling has been implicated in SP-induced proinflammatory cytokine expression. In a similar fashion to TLR4 involvement during cumulus oocyte-complex (COC) expansion where endogenous TLR4 ligands induce the expression of proinflammatory mediators important for COC expansion, such as interleukin (IL) 6 (Shimada et al. 2008), SP modulates TLR4-induced cytokines like colony-stimulating factor 2 (CSF2) (Shimada et al. 2008, Schjenken et al. 2015). The importance of SP exposure on embryonic development has also been demonstrated in mice and hamsters (Peitz \& Olds-Clarke 1986, O et al. 1988). Interestingly, many of the proinflammatory cytokines induced by SP have a physiological role as embryokines in mouse. Cytokines including CSF2 (Sjoblom et al. 2005), leukemia inhibitory factor (LIF) (Mitchell et al. 2002), IL6 (Shen et al. 2009) and tumor necrosis factorrelated apoptosis-inducing ligand (TRAIL) (Riley et al. 2004) have all been demonstrated to be important in embryo quality in the mouse or human and are shown to be regulated by SP exposure in the oviduct of mice at a time when the developing embryo is present (Bromfield et al. 2014). Indeed, the absence of SP at insemination is detrimental to the developmental progression of embryos, resulting in fewer blastocysts with increased abnormalities and fewer blastomeres (Bromfield et al. 2014).

It is now postulated that the observed SP-derived immune changes during the post-insemination period may impact the maternal adaptive immune system in preparedness for the implanting embryo, facilitating recognition and tolerance of foreign paternal antigens expressed by the subsequent conceptus. Medwar proposed the immunological paradigm of viviparity in the 1950s and postulated that specific mechanisms must exist to allow the semi-allogenic conceptus to reside within the maternal tissues throughout gestation without the threat of immunological clearance (Medwar 1953). SP itself has the capacity to modulate the function of immune cells in vitro (Anderson \& Tarter 1982, Saxena et al. 1985). However, it has become evident that SP has the capacity to also alter systemic immune function when delivered at coitus. Whereas research has demonstrated that lymphocyte populations become anergic to paternal antigens during pregnancy (Tafuri et al. 1995), an elegant study demonstrated that this hyporesponsiveness is achieved in a paternal-specific manner (Robertson et al. 1997). Robertson and colleagues demonstrated that tumor growth in female mice could be induced if mated to males with a matching MHC haplotype to that of the introduced tumor cell line. Tumor growth in virgin mice or those mated to a disparate MHC haplotype to the tumor, however, was inhibited (Robertson et al. 1997). This provides direct evidence that exposure to semen can induce systemic immune tolerance to potential paternal antigens. In 2004, a seminal paper demonstrated the importance of T-regulatory (Treg) cells in facilitating pregnancy success in mice. In the described mouse model of Treg cell depletion, no mice were observed to be pregnant in late gestation following allogeneic mating (Aluvihare et al. 2004). Whereas mating induces a transient hypertrophy of the uterine-draining lymph nodes resulting in expansion of a number of lymphocyte subpopulations, it has been demonstrated that SP or TGF $\beta$ induces antigen-specific Treg cell expansion in mice and humans (Clark et al. 2008, Guerin et al. 2011, Balandya et al. 2012, Shima et al. 2015). In addition, Kim and colleagues have identified SP-derived soluble CD38 as the active factor to induce the production of these important Treg cells and when depleted from the ejaculate of mice pregnancy failure ensued (Kim et al. 2015). Others have demonstrated the importance of SP-derived prostaglandins in expanding tolerogenic dendritic cells thought to be important in immune tolerance of pregnancy (Remes Lenicov et al. 2012). The critical role for SP-derived changes to the immune system stretch beyond what is presented here, but what does this imply for current assisted reproductive techniques and pathologies of pregnancy?

\section{The impact of semen in pregnancy pathologies and optimizing pregnancy outcomes in humans and rodents}

Current evidence is clear that SP is not required to achieve pregnancy in many species including human, rodent, domestic and wild species. In vitro fertilization (IVF) is the classic example of human conception in the absence of SP (or coitus). Several, large, wellcontrolled studies have demonstrated an increased risk of premature birth, very low birth weight, complications during delivery and serious birth defects in pregnancies derived from IVF (Perri et al. 2001, Hansen et al. 2002, Schieve et al. 2002, Wang et al. 2002, Ochsenkuhn et al. 2003. It is interesting to note a number of studies which have demonstrated a beneficial effect of SP exposure at or around the time of embryo transfer (ET) 
to improve pregnancy rates in women (Marconi et al. 1989, Tremellen et al. 2000). In addition to these causal studies, epidemiological evidence suggest that semen exposure in a partner specific manner can help to prevent pregnancy pathologies such as preeclampsia where placentation is thought to be suboptimal (KlonoffCohen et al. 1989, Robillard et al. 1995). The use of SP containing pessaries has been reported to improve pregnancy outcomes in women suffering from recurrent spontaneous abortion (Coulam \& Stern 1995). These studies and others pertaining to pregnancy pathologies suggest that the events induced by SP at insemination may 'program' the maternal environment and/ or immune system to accommodate the semi-allogeneic conceptus and optimize pregnancy outcomes. Whereas tumor studies described above indicate such treatments induces systemic changes, it is suggested that even ingestion of SP can improve reproductive outcomes in women by reducing the incidence of pre-eclampsia (Koelman et al. 2000). The authors surmise that oral exposure to paternal HLA antigens could induce maternal tolerance to paternal antigens expressed by the conceptus. Interpreting such studies is difficult, however, as the couples described likely have increased SP exposure due to increased frequency of intercourse and no mechanistic studies exist to make clear conclusions.

Our own studies in mice have demonstrated that a lack of SP exposure at conception alters the phenotype in subsequent offspring (Bromfield et al. 2014). These studies suggest that suboptimal embryonic development and placentation due to an absence of SP exposure results in offspring with increased fat deposition, increased blood pressure and altered metabolic profile. Moreover, when embryos developed for the first $48 \mathrm{~h}$ in a reproductive tract exposed to SP and then transferred to an oviduct replete of SP exposure, a similar phenotype was witnessed in female offspring, suggesting a window of susceptibility to programming due to an absence of SP exposure. These studies also described the developmental environment of the oviduct following SP exposure, suggesting that SP promoted the expression of embryokines, which may optimize developmental competence of the embryo. One of these key oviductal SP-induced embryokines is CSF2 (formerly GM-CSF). In vitro culture of human embryos has been reported to benefit from exogenous CSF2 resulting in increased development and live births (Sjoblom et al. 1999, Ziebe et al. 2013). A number of studies now suggest that the paternal contribution to pregnancy success is far greater than simple delivery of genetic material. $\mathrm{Ng}$ and colleagues demonstrated a nongenetic transmission of paternal phenotype in rats fed a high-fat diet $(\mathrm{Ng}$ et al. 2010). Male rats fed a high-fat diet produced female offspring with impaired glucose tolerance and $\beta$-cell dysfunction independent of fat deposition. An interesting paradigm of SP exposure has recently been described, which possibly pertains to the immune-modulating ability of SP. Xenografting of human endometriosis lesions to nude mice has shown that exposure to SP promotes lesion growth (McGuane et al. 2015). These studies suggest that the immunomodulatory properties of SP may indeed be detrimental to certain pathological conditions such as endometriosis.

Collectively, the studies presented here (and others) are suggestive of a beneficial role of SP exposure to promote early pregnancy success in women and rodents by modulating the maternal immune response to the conceptus and promoting early embryonic development. Rodent studies elude to maternal SP exposure contributing to programing the health of subsequent offspring (Fig. 1).

\section{Can the benefits of SP be extrapolated to domestic species?}

The role of SP in altering the maternal environment is now well documented in mice and may extend to humans. However, agriculturally and economically important domestic species have yet to be investigated to the same extent.

Reproduction in many relevant domestic species including poultry, horses, sheep, cows and pigs is being managed very efficiently by commercial producers to optimize the genetic merit of offspring by using reproductive technologies such as AI. During the processing of semen to increase the number of applicable inseminations from a single ejaculate SP is either removed or considerably diluted, while the volume of semen used during $\mathrm{Al}$ is markedly reduced compared with that of natural insemination. All of these factors could potentially reduce the efficacy of any active moieties present in semen, and consequently reduce any positive effects on reproductive outcomes. For example, an average Holstein bull produces $3.75 \mathrm{~mL}$ of semen per ejaculate containing a total of $5000 \times 10^{6}$ sperm. If a single $\mathrm{Al}$ dose requires $5 \times 10^{6}$ sperm in $0.25 \mathrm{~mL}$, the initial ejaculate would provide 1000 inseminations resulting in a dilution of SP in semen extender by a factor of 332 (numbers adapted from Den Daas et al. (1998) and Hering et al. (2014)).

\section{$S P$ signaling and bovine reproduction}

Much of the modern bovine dairy industry relies heavily on $\mathrm{Al}$ and the use of high genetic merit sires, while the beef industry still uses a high proportion of live bull cover (natural insemination). To date, only a single study has evaluated the ability of semen to induce inflammation in the endometrium of cattle (Mahajan \& Menge 1967), while the effect of SP is yet to be determined. However, studies have demonstrated that the presence of SP does alter sperm parameters including viability and motility (Baas et al. 1983). SP has also been demonstrated to 
increase neutrophil binding to sperm in the bovine (Alghamdi et al. 2009). Conversely, the addition of SP at very low concentrations $(0.2 \% \mathrm{v} / \mathrm{v})$ to in vitro assays using peripheral blood leukocytes was shown to reduce net migration and reactive oxygen production while increasing cell membrane damage (Aloe et al. 2012), further suggesting a role of SP in modulating local inflammatory response.

In induced ovulatory species such as camelids (including the Ilama), SP contains specific ovulationinducing factors like $\beta$-nerve growth factor ( $\beta$-NGF) (Ratto et al. 2012). Whereas the bovine is not an inducible ovulatory, it is interesting to note that bovine SP also contains $\beta$-NGF (Tribulo et al. 2015). Bovine SP has the capacity to induce ovulation in the Ilama in addition to acting as a luteotrophic agent by promoting progesterone secretion when administered as an intramuscular injection in cattle (Tribulo et al. 2015). Proteomics has verified the presence of $\beta$-NGF in bovine SP in addition to 98 other identified proteins including BSP-PDC109 (BSP-A1/A2), BSP-A3 and BSP$30 \mathrm{kDa}$, which comprise approximately half of all the proteins in SP (Manjunath \& Sairam 1987, Desnoyers et al. 1994, Kelly et al. 2006). Whereas the chemokine monocyte chemoattractant protein 1 (MCP1, known as CCL2) was identified in bovine SP, these papers were unable to identify other immune-modulating factors including TGF $\beta$, which is known to exist in SP of other species. Using ELISA we have been able to quantify the presence of total TGF $\beta$ isoforms 1 and 2 in SP of 33 bulls $(7.11 \pm 1.55$ and $6.07 \pm 1.16 \mathrm{ng} / \mathrm{mL}$ respectively).

The ability of SP to increase pregnancy outcomes in cow is of great interest. In 1968, the importance of the seminal vesicle glands in the bull were tested by surgical removal (resulting in increase in sperm concentration due to a halving in ejaculate volume) and subsequent breeding of bulls to heifers (Faulkner et al. 1968). Minimal impact on sperm motility and viability was observed in bulls following seminal vesicle removal. Surprisingly, when seminal vesicledeficient bulls were bred to heifers a $60 \%$ conception rate was still observed (Table 1). These findings may be due to the fact that the seminal vesicles only contribute half of the total volume of SP to the ejaculate, while the Cowper's and prostate glands may be significantly more important in the bovine than in rodents where $90 \%$ of SP is seminal vesicle derived. Importantly, these studies did not use intact control bulls when assessing fertility, which does not allow the interpretation that the seminal vesicles are not essential to fertility in the bull as concluded by the authors.

Odhiambo and colleagues (2009) demonstrated that exposure to SP around the time of AI numerically increased pregnancy rates at day $35-40$ by $13.9 \%$ in dairy cows (this was not statistically significant). An interesting observation from the same study reported that when reproductive performance was optimal,
SP (or the known active moiety in the rodent, TGF $\beta$ ) had no effect on pregnancy rates. However when reproductive performance was suboptimal (which readily occurs) administration of TGF $\beta$ improved conception rates by $28.1 \%$.

\section{SP signaling and porcine reproduction}

Natural insemination in pig occurs intracervically resulting in up to $500 \mathrm{~mL}$ of ejaculate being deposited in the uterus of the sow. This process is considerably different to all other species discussed here where insemination normally results in semen being deposited in the vagina near the external os of the cervix. The fact that semen is deposited into the pig's uterus lends a unique opportunity for SP to directly interact with the endometrium. Indeed, prototypic inflammation in the endometrium is observed $34 \mathrm{~h}$ after the infusion of SP in pig denoted by increased CD45+, MHCII+ and HB142+ (macrophages) cells (O'Leary et al. 2004). These studies show that SP-induced inflammation is greatest 5 days after treatment and in some cases still evident up to 9 days following SP infusion. Conversely, it has been shown that sperm alone can increase luminal leukocytes and when sperm is administered in conjunction with SP a reduction in luminal leukocytes is observed within $36 \mathrm{~h}$ of treatment (Rozeboom et al. 1999).

Sperm survival and motility are improved when stored in SP compared with samples washed and stored in commercial extenders (Chutia et al. 2014). A subsequent bonus of improved sperm quality may be the observed increase in early embryos when $\mathrm{Al}$ is followed by exposure to SP. An increase in the average number of total and viable embryos collected from pigs up to day nine following Al was observed when SP is infused at insemination (O'Leary et al. 2004). In this regard, it is important to also consider the observed effects of SP on the ovary, which may contribute to increased embryonic viability in pig (or cow as discussed above). Intrauterine SP infusion significantly increases plasma progesterone, corpus luteum weight and infiltration of leukocytes into ovarian tissue, all of which may change the developmental competency of ovulated oocytes and early embryo survival (O'Leary et al. 2006).

Notwithstanding the documented actions of SP on the maternal tissues and early pregnancy discussed here, it is interesting to note that of the species studied in regard to SPs action, pig has the least invasive placenta and likely requires the least immune modulation of the species discussed.

\section{$S P$ signaling and equine reproduction}

Similar to the species discussed already, commercial horse reproduction (with the exception of thoroughbreds) relies heavily on Al using washed, SP-free sperm. A number of studies have demonstrated the potential of SP 
Table 1 Effect of seminal vesicle removal on bull fertility.

\begin{tabular}{|c|c|c|c|c|c|}
\hline Bull ID & & Volume $(\mathrm{mL})$ & Concentration score & Heifers bred & Conception rate $(\%)$ \\
\hline \multirow[t]{2}{*}{2172} & Before & 2.7 & 3.2 & & \\
\hline & After & $1.7^{*}$ & $4.1^{*}$ & 7 & 71 \\
\hline \multirow[t]{2}{*}{2240} & Before & 3.2 & 2.9 & & \\
\hline & After & $1.3^{*}$ & $3.9^{*}$ & 8 & 75 \\
\hline \multirow[t]{2}{*}{3018} & Before & 6.2 & 4.1 & & \\
\hline & After & 3.5 & $4.5^{*}$ & 16 & 75 \\
\hline \multirow[t]{2}{*}{3024} & Before & 4.9 & 4.0 & & \\
\hline & After & $3.0^{*}$ & $4.9^{*}$ & - & - \\
\hline \multirow[t]{2}{*}{3053} & Before & 6.3 & 3.9 & & \\
\hline & After & $2.5^{*}$ & 3.8 & 5 & 40 \\
\hline \multirow[t]{2}{*}{ Average } & Before & 5.1 & 3.8 & & \\
\hline & After & $2.7^{*}$ & $4.8^{*}$ & 36 & 69 \\
\hline
\end{tabular}

*Significant from 'before' value.

Adapted from Faulkner et al. (1968).

to increase horse and donkey sperm fertility, especially following cryopreservation (Neuhauser et al. 2015). Recently, lipidomics has identified novel lipids in horse SP including phosphatidylethanolamines (PtdEs) that are absent in sperm (Wood et al. 2016). Whereas the authors conclude that PtdEs may protect sperm or contribute to capacitation, it is important to understand that these lipids are a common component of bacterial and mitochondrial membranes and secretory vesicles (Dowhan 1997, Marsh 2007, van Meer et al. 2008), suggesting either potential contamination of semen by bacteria or the potential for vesicle signaling in SP.

The horse has a unique problem of inseminationinduced endometritis, which has increased with the use of SP-free Al. Interestingly, when endometrial inflammation was measured in response to SP in horse, similar increases in leukocyte infiltrate and immune mediator expression were observed when compared with infusion of sterile PBS (Palm et al. 2008), suggesting mechanical stimulation of inflammation in horse, possibly due to the application of excess fluid volume in the uterus. It has been suggested that SP regulates inflammation in the equine to mediate inflammation resolution. When $\mathrm{SP}$ is infused at $\mathrm{Al}$, the duration of postinsemination inflammation is shortened compared with horses undergoing standard SP-free Al (Troedsson et al. 2001). Similarly, when SP is added to semen for AI and used in animals with induced inflammation using heatkilled sperm, pregnancy rates of $77 \%$ were achieved, while only $5 \%$ of mares became pregnant in the absence of SP (Alghamdi et al. 2004). Whereas the properties of SP to protect sperm during inflammation in the equine reproductive tract are novel when compared with other species, the ability for SP to improve conception rates in horse mirrors that of other species. When sperm are resuspended into SP after cryopreservation, conception rates in the donkey were increased $166 \%$ compared with commercial extender (Rota et al. 2012). However, there exist a number of studies that suggest a negative effect of SP on the cryosurvival of equine sperm at higher concentrations (above 5\%) (Brinsko et al. 2000, Aurich 2008). The conflicting data between improved and decreased sperm parameters may be in part due to variation of SP composition between stallions and/or preservation protocols (Aurich et al. 1996). Anecdotally, it would appear that semen preparation for freezing and storage uses the near-complete removal of SP by centrifugation as the industry standard. A greater depth of exploration is required in horse reproductive capabilities to improve reproductive efficiency and the contribution that SP may play in reproductive outcomes.

\section{SP signaling and ovine reproduction}

Currently, natural conception using live ram cover is the standard practice in the sheep industry. However, following the advent of genetic selection $\mathrm{Al}$ is becoming increasingly popular among sheep producers. In addition, sheep are seasonal breeders (breeding in the autumn months), which places additional constraints on the producers to breed their animals quickly and efficiently over a short time, something which could potentially be improved by Al. However, Al in sheep is currently technically challenging due to the anatomical structure of the cervix that is restrictive to the passage of an intrauterine inseminating device. Currently, Al in sheep requires the use of highly skilled laparoscopic insemination of semen directly into the uterus.

Following live cover of ewes with fertile rams, acute changes in the cellular distribution and abundance of leukocytes in the cervix and uterus is observed compared with non-mated ewes at estrus (Mattner 1969, Scott et al. 2006). Neutrophil density is increased in the cervix and uterus $6 \mathrm{~h}$ after insemination, while macrophage number in the uterus peaks $24 \mathrm{~h}$ following insemination, mirroring cellular distribution seen in rodents and humans. Interestingly, inflammatory response of the ewe endometrium to semen or SP is dependent on the estrous cycle stage (Scott et al. 2006). Whole semen, SP and sperm induces an inflammatory response in the endometrium of ewes at estrus, increasing neutrophils, CSF2 and IL-8 secretion, while no inflammation is observed in ewes exposed to SP at diestus. It is interesting to note, however, that when antibiotics 
where administered in combination with semen or SP, inflammation was reduced, suggesting a confounding influence of contaminating bacteria. The fact that ewes respond differently to the ejaculate depending on estrous cycle stage corresponds to the changes in the proteome of ram SP, and may have implications in the seasonal breeding of sheep (Smith et al. 1997, Perez-Pe et al. 2001, Cardozo et al. 2006). Additional proteomic analysis of ram SP has revealed striking similarities with the most abundant proteins of bovine SP, namely the presence of BSP A1/A2-like protein accounting for 34\% of protein in ram SP (Jobim et al. 2005).

With the increased advancements of sperm freezing and application of $\mathrm{Al}$ in sheep, further research is required to determine if SP-induced endometrial inflammation can benefit pregnancy outcomes in domestic sheep breeds.

\section{Current reproductive strategies in domestic species and the potential role for $S P$}

As noted above, the application of reproductive technologies in agricultural production of domestic species is implemented to ensure high productivity, maximize efficiency and increase genetic merit of offspring. The use of exogenous hormones for estrous cycle regulation and ovarian stimulation, semen collection, $\mathrm{Al}$, gamete freezing, IVF, embryo transfer (ET) and sperm sex sorting are now common place in many species; none more so than in the dairy cow industry where all of these technologies are used routinely and many of which were first developed and later implemented in humanassisted reproduction. The successful implementation of IVF/ET and Al demonstrate that SP is not required to achieve pregnancy. In fact, it has been demonstrated many times that IVF/ET pregnancy rates exceed those of timed $\mathrm{Al}$ in the dairy industry (Vasconcelos et al. 2006, Demetrio et al. 2007, Vasconcelos et al. 2011, Pellegrino et al. 2016). However, it is known that early pregnancy loss, including fertilization failure and embryonic death are leading causes of pregnancy failure in the dairy industry (reviewed in Wiltbank et al. (2016)). The technology of ET itself bypasses very early pregnancy loss in cow by ensuring fertilization and the first 5-7 days of embryonic development have been completed before introducing the embryo into the female reproductive tract, giving a plausible reason why ET generates higher pregnancy rates than traditional or timed Al. Interestingly, gene expression studies of the oviduct in which the early embryo develops show little change due to the presence of an embryo following transfer in the absence of SP (Maillo et al. 2015). In fact, further studies reveal that gene expression in the oviduct isthmus following $\mathrm{Al}$ is unchanged by the presence of an embryo when compared with oviductal cells at estrus (Maillo et al. 2016). The authors conclude from these studies that gene expression in the oviduct, and subsequent production of embryokines, is dependent only on estrous cycle stage. However, no studies in cow have shown responsiveness of oviductal cells to SP or its active components; conversely in the mouse oviductal gene expression of embryokines is significantly upregulated following coital exposure to SP (Bromfield et al. 2014). The potential of SP to modulate the early embryonic developmental environment of the oviduct remains to be suitably investigated.

The application of sex-sorting sperm by flow cytometry in the dairy industry is common place and used to increase the potential of female offspring to maximize milk production of the herd (giving rise to milking cows). The negative impact of SP on sex sorting is interesting and important to such a valuable technology. Burroughs and colleagues have shown that the inclusion of SP from 5 to $20 \%$ has negative consequences on the sort rate of X-sperm in addition to reducing post-thaw motility of sperm compared with sperm washed free of SP (Burroughs et al. 2013). In this regard, it may be a best practice to remove SP before sex sorting and potentially supplement SP at the time of Al.

Recapitulating the normal developmental environment of the embryo, implantation, placentation and fetal development is key to optimizing currently used reproductive technologies in domestic species. Whereas SP is not required for pregnancy, small improvements to reproductive performance in domestic species could have large economic (and potentially environmental) impacts on production efficiency. More research is required to determine if the application or supplementation of SP, or its active components, could improve reproductive efficiency for domestic species production and potentially even alter postnatal development of offspring as described in the rodent (Bromfield et al. 2014).

\section{Conclusions}

The mechanistic role of SP in rodent reproduction continues to be defined at a cellular and molecular level and suggests that SP can improve reproductive outcomes and potentially even the health and development of offspring. However, it remains to be seen whether a similar role for SP exists in domestic species where it is becoming common practice to remove SP from the reproductive equation. Whereas it is clear that SP is not required for successful pregnancy, incremental improvements to reproductive outputs in domestic species can bear financial and environmental impacts. If the influence of SP on programming health in offspring is recapitulated in domestic species, increased growth, production, sustainability and efficiency in agriculture could potentiate astonishing global impacts. It is our aim to continue to expand on the knowledge of how SP can help us improve the reproductive efficiency of our 
domestic species for the benefit of human health and well-being.

\section{Declaration of interest}

The authors declare that there is no conflict of interest that could be perceived as prejudicing the impartiality of this review.

\section{Funding}

Funding for ongoing seminal plasma research is supported by Select Sires Inc and the Southeast Milk Checkoff.

\section{References}

Alghamdi AS, Foster DN \& Troedsson MH 2004 Equine seminal plasma reduces sperm binding to polymorphonuclear neutrophils (PMNs) and improves the fertility of fresh semen inseminated into inflamed uteri. Reproduction 127 593-600. (doi:10.1530/rep.1.00096)

Alghamdi AS, Lovaas BJ, Bird SL, Lamb GC, Rendahl AK, Taube PC \& Foster DN 2009 Species-specific interaction of seminal plasma on sperm-neutrophil binding. Animal Reproduction Science 114 331-344. (doi:10.1016/j.anireprosci.2008.10.015)

Aloe S, Weber F, Behr B, Sauter-Louis C \& Zerbe H 2012 Modulatory effects of bovine seminal plasma on uterine inflammatory processes. Reproduction in Domestic Animals 47 12-19. (doi:10.1111/j.14390531.2011.01792.x)

Aluvihare VR, Kallikourdis M \& Betz AG 2004 Regulatory T cells mediate maternal tolerance to the fetus. Nature Immunology 5 266-271. (doi:10.1111/j.1365-2621.2005.tb07114.x)

Anderson DJ \& Tarter TH 1982 Immunosuppressive effects of mouse seminal plasma components in vivo and in vitro. Journal of Immunology 128 535-539.

Aurich C 2008 Recent advances in cooled-semen technology. Animal Reproduction Science $\mathbf{1 0 7}$ 268-275. (doi:10.1016/j. anireprosci.2008.04.015)

Aurich JE, Kuhne A, Hoppe H \& Aurich C 1996 Seminal plasma affects membrane integrity and motility of equine spermatozoa after cryopreservation. Theriogenology 46 791-797. (doi:10.1016/S0093691X(96)00237-3)

Avila FW, Sirot LK, LaFlamme BA, Rubinstein CD \& Wolfner MF 2011 Insect seminal fluid proteins: identification and function. Annual Review of Entomology 56 21-40. (doi:10.1146/annurevento-120709-144823)

Baas JW, Molan PC \& Shannon P 1983 Factors in seminal plasma of bulls that affect the viability and motility of spermatozoa. Journal of Reproduction and Fertility 68 275-280. (doi:10.1530/jrf.0.0680275)

Balandya E, Wieland-Alter W, Sanders K \& Lahey T 2012 Human seminal plasma fosters $\mathrm{CD} 4(+)$ regulatory $\mathrm{T}$-cell phenotype and transforming growth factor-beta1 expression. American Journal of Reproductive Immunology 68 322-330. (doi:10.1111/j.1600-0897.2012.01176.x)

Brinsko SP, Crockett EC \& Squires EL 2000 Effect of centrifugation and partial removal of seminal plasma on equine spermatozoal motility after cooling and storage. Theriogenology 54 129-136. (doi:10.1002/ jsfa.2740340513)

Bromfield JJ, Schjenken JE, Chin PY, Care AS, Jasper MJ \& Robertson SA 2014 Maternal tract factors contribute to paternal seminal fluid impact on metabolic phenotype in offspring. PNAS 111 2200-2205. (doi:10.1073/ pnas.1305609111)

Burroughs CA, Graham JK, Lenz RW \& Seidel GE Jr., 2013 Seminal plasma effects on sex-sorting bovine sperm. Theriogenology 79 551-557. (doi:10.2527/2006.8451221x)

Cardozo JA, Fernandez-Juan M, Forcada F, Abecia A, Muino-Blanco T \& Cebrian-Perez JA 2006 Monthly variations in ovine seminal plasma proteins analyzed by two-dimensional polyacrylamide gel electrophoresis. Theriogenology $66 \quad 841-850$. (doi:10.1016/j. theriogenology.2006.01.058)
Chutia T, Biswas RK, Tamuli MK, Deka BC, Sinha S, Goswami J, Banik S \& Kayastha RB 2014 Effect of holding of semen and washing of seminal plasma on quality and fertility of Hampshire boar semen preserved at liquid state. Animal Reproduction Science 145 141-149. (doi:10.1016/j. anireprosci.2014.01.007)

Clark DA, Fernandes J \& Banwatt D 2008 Prevention of spontaneous abortion in the CBA $\times$ DBA/2 mouse model by intravaginal TGFbeta and local recruitment of CD4+8+ FOXP3+ cells. American Journal of Reproductive Immunology 59 525-534. (doi:10.1016/j. meatsci.2013.12.013)

Coulam CB \& Stern JJ 1995 Effect of seminal plasma on implantation rates. Early Pregnancy 1 33-36.

Demetrio DG, Santos RM, Demetrio CG \& Vasconcelos JL 2007 Factors affecting conception rates following artificial insemination or embryo transfer in lactating Holstein cows. Journal of Dairy Science $\mathbf{9 0}$ 5073-5082. (doi:10.3168/jds.2007-0223)

Den Daas JH, De Jong G, Lansbergen LM \& Van Wagtendonk-De Leeuw AM 1998 The relationship between the number of spermatozoa inseminated and the reproductive efficiency of individual dairy bulls. Journal of Dairy Science 81 1714-1723. (doi:10.1016/j.meatsci.2007.07.025)

Desnoyers L, Therien I \& Manjunath P 1994 Characterization of the major proteins of bovine seminal fluid by two-dimensional polyacrylamide gel electrophoresis. Molecular Reproduction and Development 37 425-435. (doi:10.1002/mrd.1080370409)

Dowhan W 1997 Molecular basis for membrane phospholipid diversity: why are there so many lipids? Annual Review of Biochemistry 66 199-232. (doi:10.1146/annurev.biochem.66.1.199)

Faulkner LC, Hopwood ML \& Wiltbank JN 1968 Seminal vesiculectomy in bulls. II. Seminal characteristics and breeding trials. Journal of Reproduction and Fertility 16 179-182. (doi:10.1530/jrf.0.0160179)

Guerin LR, Moldenhauer LM, Prins JR, Bromfield JJ, Hayball JD \& Robertson SA 2011 Seminal fluid regulates accumulation of FOXP3+ regulatory $\mathrm{T}$ cells in the preimplantation mouse uterus through expanding the FOXP3+ cell pool and CCL19-mediated recruitment. Biology of Reproduction 85 397-408. (doi:10.1095/biolreprod.110.088591)

Gutsche S, von Wolff M, Strowitzki T \& Thaler CJ 2003 Seminal plasma induces mRNA expression of IL-1 beta, IL-6 and LIF in endometrial epithelial cells in vitro. Molecular Human Reproduction 9 785-791. (doi:10.1093/molehr/gag095)

Hansen M, Kurinczuk JJ, Bower C \& Webb S 2002 The risk of major birth defects after intracytoplasmic sperm injection and in vitro fertilization. New England Journal of Medicine 346 725-730. (doi:10.1056/ NEJMoa010035)

Hering DM, Olenski K, Rusc A \& Kaminski S 2014 Genome-wide association study for semen volume and total number of sperm in Holstein-Friesian bulls. Science 151 126-130. (doi:10.1016/j. anireprosci.2014.10.022)

Jobim MI, Oberst ER, Salbego CG, Wald VB, Horn AP \& Mattos RC 2005 BSP A1/A2-like proteins in ram seminal plasma. Theriogenology 63 2053-2062. (doi:10.1016/j.theriogenology.2004.10.002)

Kelly VC, Kuy S, Palmer DJ, Xu Z, Davis SR \& Cooper GJ 2006 Characterization of bovine seminal plasma by proteomics. Proteomics $\mathbf{6}$ 5826-5833. (doi:10.1002/pmic.200500830)

Kim BJ, Choi YM, Rah SY, Park DR, Park SA, Chung YJ, Park SM, Park JK, Jang KY \& Kim UH 2015 Seminal CD38 is a pivotal regulator for fetomaternal tolerance. PNAS 112 1559-1564. (doi:10.1073/ pnas.1413493112)

Klonoff-Cohen HS, Savitz DA, Celafo RC \& McCann MF 1989 An epidemiologic study of contraception and preeclampsia. Journal of the American Medical Association 262 3143-3147. (doi:10.1001/ jama.1989.03430220066032)

Koelman CA, Coumans AB, Nijman HW, Doxiadis II, Dekker GA \& Claas FH 2000 Correlation between oral sex and a low incidence of preeclampsia: a role for soluble HLA in seminal fluid? Journal of Reproductive Immunology 46 155-166. (doi:10.1016/S01650378(99)00062-5)

Mahajan SC \& Menge AC 1967 Influence of reproductive phase on the inflammatory response and rate of sperm removal in the uterus and oviduct of the cow. American Journal of Veterinary Research $\mathbf{2 8}$ 1037-1041.

Maillo V, Gaora PO, Forde N, Besenfelder U, Havlicek V, Burns GW, Spencer TE, Gutierrez-Adan A, Lonergan P \& Rizos D 2015 
Oviduct-embryo interactions in cattle: two-way traffic or a one-way street? Biology of Reproduction 92 144. (doi:10.1095/biolreprod.115.127969) Maillo V, de Frutos C, O'Gaora P, Forde N, Burns GW, Spencer TE, Gutierrez-Adan A, Lonergan P \& Rizos D 2016 Spatial differences in gene expression in the bovine oviduct. Reproduction 152 37-46. (doi:10.1530/REP-16-0074)

Manjunath P \& Sairam MR 1987 Purification and biochemical characterization of three major acidic proteins (BSP-A1, BSP-A2 and BSP-A3) from bovine seminal plasma. Biochemical Journal 241 685-692. (doi:10.1042/bj2410685)

Marconi G, Auge L, Oses R, Quintana R, Raffo F \& Young E 1989 Does sexual intercourse improve pregnancy rates in gamete intrafallopian transfer? Fertiligy and Sterility 51 357-359. (doi:10.1016/S00150282(16)60507-1)

Marsh D 2007 Lateral pressure profile, spontaneous curvature frustration, and the incorporation and conformation of proteins in membranes. Biophysical Journal 93 3884-3899. (doi:10.1529/biophysj.107.107938)

Mattner PE 1969 Differential leucocytic responses to spermatozoa in the cervix and the uterus in ewes. Journal of Reproduction and Fertility $\mathbf{1 8}$ 297-303. (doi:10.1530/jrf.0.0180297)

McGuane JT, Watson KM, Zhang J, Johan MZ, Wang Z, Kuo G, Sharkey DJ, Robertson SA \& Hull ML 2015 Seminal Plasma Promotes Lesion Development in a Xenograft Model of Endometriosis. American Journal of Pathology 185 1409-1422. (doi:10.1016/0309-1740(92)90086-J)

Medwar P 1953 Some immunological and endocrinological problems raised by the evolution of viviparity in vertebrates. Symposia of the Society for Experimental Biology 7 320-338.

Mitchell MH, Swanson RJ \& Oehninger S 2002 In vivo effect of leukemia inhibitory factor (LIF) and an anti-LIF polyclonal antibody on murine embryo and fetal development following exposure at the time of transcervical blastocyst transfer. Biology of Reproduction 67 460-464. (doi:10.1095/biolreprod67.2.460)

Neuhauser S, Dorfel S \& Handler J 2015 Dose-dependent effects of homologous seminal plasma on motility and kinematic characteristics of post-thaw stallion epididymal spermatozoa. Andrology 3 536-543. (doi:10.1111/andr.12003)

Ng SF, Lin RC, Laybutt DR, Barres R, Owens JA \& Morris MJ 2010 Chronic high-fat diet in fathers programs beta-cell dysfunction in female rat offspring. Nature 467 963-966. (doi:10.1038/nature09491)

O'Leary S, Jasper MJ, Robertson SA \& Armstrong DT 2006 Seminal plasma regulates ovarian progesterone production, leukocyte recruitment and follicular cell responses in the pig. Reproduction 132 147-158. (doi:10.1530/rep.1.01119)

O'Leary S, Jasper MJ, Warnes GM, Armstrong DT \& Robertson SA 2004 Seminal plasma regulates endometrial cytokine expression, leukocyte recruitment and embryo development in the pig. Reproduction 128 237-247. (doi:10.1530/rep.1.00160)

O WS, Chen HQ \& Chow PH 1988 Effects of male accessory sex gland secretions on early embryonic development in the golden hamster Journal of Reproduction and Fertility 84 341-344. (doi:10.1007/s00335003-2286-8)

Ochsenkuhn R, Strowitzki T, Gurtner M, Strauss A, Schulze A, Hepp H \& Hillemanns P 2003 Pregnancy complications, obstetric risks, and neonatal outcome in singleton and twin pregnancies after GIFT and IVF. Archives of Gynecology and Obstetrics 268 256-261. (doi:10.2527/ jas1979.4861343x)

Odhiambo JF, Poole DH, Hughes L, Dejarnette JM, Inskeep EK \& Dailey RA 2009 Pregnancy outcome in dairy and beef cattle after artificial insemination and treatment with seminal plasma or transforming growth factor beta-1. Theriogenology 72 566-571. (doi:10.1016/j. theriogenology.2009.04.013)

Palm F, Walter I, Budik S, Kolodziejek J, Nowotny N \& Aurich C 2008 Influence of different semen extenders and seminal plasma on PMN migration and on expression of IL-1beta, IL-6, TNF-alpha and COX2 mRNA in the equine endometrium. Theriogenology 70 843-851. (doi:10.1016/j.theriogenology.2008.04.054)

Peitz B \& Olds-Clarke P 1986 Effects of seminal vesicle removal on fertility and uterine sperm motility in the house mouse. Biology of Reproduction 35 608-617. (doi:10.1095/biolreprod35.3.608)

Pellegrino CA, Morotti F, Untura RM, Pontes JH, Pellegrino MF, Campolina JP, Seneda MM, Barbosa FA \& Henry M 2016 Use of sexed sorted semen for fixed-time artificial insemination or fixed-time embryo transfer of in vitro-produced embryos in cattle. Theriogenology $\mathbf{8 6}$ 888-893. (doi:10.1016/j.theriogenology.2016.03.010)

Perez-Pe R, Barrios B, Muino-Blanco T \& Cebrian-Perez JA 2001 Seasonal differences in ram seminal plasma revealed by partition in an aqueous two-phase system. Journal of Chromatography. B, Biomedical Sciences and Applications 760 113-121. (doi:10.1016/S0378-4347(01)00259-6)

Perri T, Chen R, Yoeli R, Merlob P, Orvieto R, Shalev Y, Ben-Rafael Z \& Bar-Hava I 2001 Are singleton assisted reproductive technology pregnancies at risk of prematurity? Journal of assisted Reproduction and Genetics 18 245-249. (doi:10.1023/A:1016614217411)

Ratto MH, Leduc YA, Valderrama XP, van Straaten KE, Delbaere LT, Pierson RA \& Adams GP 2012 The nerve of ovulation-inducing factor in semen. PNAS 109 15042-15047. (doi:10.1073/pnas.1206273109)

Remes Lenicov F, Rodriguez Rodrigues C, Sabatte J, Cabrini M, Jancic C, Ostrowski M, Merlotti A, Gonzalez H, Alonso A, Pasqualini RA et al. 2012 Semen promotes the differentiation of tolerogenic dendritic cells. Journal of Immunology 189 4777-4786. (doi:10.4049/ jimmunol.1202089)

Riley JK, Heeley JM, Wyman AH, Schlichting EL \& Moley KH 2004 TRAIL and KILLER are expressed and induce apoptosis in the murine preimplantation embryo. Biology of Reproduction 71 871-877. (doi:10.1095/biolreprod.103.026963)

Robertson SA 2005 Seminal plasma and male factor signalling in the female reproductive tract. Cell and Tissue Research 322 43-52. (doi:10.1007/ s00441-005-1127-3)

Robertson SA, Mau VJ, Tremellen KP \& Seamark RF 1996 Role of high molecular weight seminal vesicle proteins in eliciting the uterine inflammatory response to semen in mice. Journal of Reproduction and Fertility 107 265-277. (doi:10.1530/jrf.0.1070265)

Robertson SA, Mau VJ, Hudson SN \& Tremellen KP 1997 Cytokineleukocyte networks and the establishment of pregnancy. American Journal of Reproductive Immunology 37 438-442. (doi:10.1111/j.1600-0897.1997.tb00257.x)

Robillard PY, Hulsey TC, Perianin J, Janky E, Miri EH \& Papiernik E 1995 Association of pregnancy-induced hypertension with duration of sexual cohabitation before conception. Lancet 344 973-975. (doi:10.1016/ S0140-6736(94)91638-1)

Rota A, Panzani D, Sabatini C \& Camillo F 2012 Donkey jack (Equus asinus) semen cryopreservation: studies of seminal parameters, post breeding inflammatory response, and fertility in donkey jennies. Theriogenology 78 1846-1854. (doi:10.1016/j.theriogenology.2012.07.015)

Rozeboom KJ, Troedsson MH, Molitor TW \& Crabo BG 1999 The effect of spermatozoa and seminal plasma on leukocyte migration into the uterus of gilts. Journal of Animal Science 77 2201-2206. (doi:10.2527/1999.7782201x)

Saxena S, Jha P \& Farooq A 1985 Immunosuppression by human seminal plasma. Immunological Investigations $14 \quad 255-269$. (doi:10.3109/08820138509076149)

Schieve LA, Meikle SF, Ferre C, Peterson HB, Jeng G \& Wilcox LS 2002 Low and very low birth weight in infants conceived with use of assisted reproductive technology. New England Journal of Medicine 346 731-737. (doi:10.1056/NEJMoa010806)

Schjenken JE, Glynn DJ, Sharkey DJ \& Robertson SA 2015 TLR4 Signaling Is a Major Mediator of the Female Tract Response to Seminal Fluid in Mice. Biology of Reproduction 93 68. (doi:10.1095/biolreprod.114.125740)

Scott JL, Ketheesan N \& Summers PM 2006 Leucocyte population changes in the reproductive tract of the ewe in response to insemination. Reproduction, Fertility, and Development 18 627-634. (doi:10.1071/ RD05165)

Seok J, Warren HS, Cuenca AG, Mindrinos MN, Baker HV, Xu W, Richards DR, McDonald-Smith GP, Gao H, Hennessy L et al. 2013 Genomic responses in mouse models poorly mimic human inflammatory diseases. PNAS 110 3507-3512. (doi:10.1073/ pnas.1222878110)

Sharkey DJ, Macpherson AM, Tremellen KP, Mottershead DG, Gilchrist RB \& Robertson SA 2012a TGF-beta mediates proinflammatory seminal fluid signaling in human cervical epithelial cells. Journal of Immunology 189 1024-1035. (doi:10.4049/jimmunol.1200005)

Sharkey DJ, Tremellen KP, Jasper MJ, Gemzell-Danielsson K \& Robertson SA $2012 b$ Seminal fluid induces leukocyte recruitment and cytokine and chemokine mRNA expression in the human cervix after coitus. Journal of Immunology 188 2445-2454. (doi:10.4049/jimmunol.1102736) 
Shen XH, Han YJ, Zhang DX, Cui XS \& Kim NH 2009 A link between the interleukin-6/Stat3 anti-apoptotic pathway and microRNA-21 in preimplantation mouse embryos. Molecular Reproduction and Development 76 854-862. (doi:10.1002/mrd.21048)

Shima T, Inada K, Nakashima A, Ushijima A, Ito M, Yoshino O \& Saito S 2015 Paternal antigen-specific proliferating regulatory $\mathrm{T}$ cells are increased in uterine-draining lymph nodes just before implantation and in pregnant uterus just after implantation by seminal plasma-priming in allogeneic mouse pregnancy. Journal of Reproductive Immunology 108 72-82. (doi:10.1016/j.jri.2015.02.005)

Shimada M, Yanai Y, Okazaki T, Noma N, Kawashima I, Mori T \& Richards JS 2008 Hyaluronan fragments generated by sperm-secreted hyaluronidase stimulate cytokine/chemokine production via the TLR2 and TLR4 pathway in cumulus cells of ovulated COCs, which may enhance fertilization. Development 135 2001-2011. (doi:10.1242/dev.020461)

Sjoblom C, Wikland M \& Robertson SA 1999 Granulocytemacrophage colony-stimulating factor promotes human blastocyst development in vitro. Human Reproduction 14 3069-3076. (doi:10.1111/j.1365-2621.2002.tb09584.x)

Sjoblom C, Roberts CT, Wikland M \& Robertson SA 2005 Granulocytemacrophage colony-stimulating factor alleviates adverse consequences of embryo culture on fetal growth trajectory and placental morphogenesis. Endocrinology 146 2142-2153. (doi:10.1210/en.2004-1260)

Smith JF, Parr J, Smith JK, Briggs RM \& Duganzich DM 1997 Seasonal patterns in production and quality of semen of rams from flocks selected for or against an early breeding season. Proceedings of the New Zealand Society of Animal Production $\mathbf{5 7} 259$.

Tafuri A, Alferink J, Moller P, Hammerling GJ \& Arnold B 1995 T cell awareness of paternal alloantigens during pregnancy. Science $\mathbf{2 7 0}$ 630-633. (doi:10.1126/science.270.5236.630)

Tremellen KP, Seamark RF \& Robertson SA 1998 Seminal transforming growth factor beta1 stimulates granulocyte-macrophage colonystimulating factor production and inflammatory cell recruitment in the murine uterus. Biology of Reproduction 58 1217-1225. (doi:10.1095/ biolreprod58.5.1217)

Tremellen KP, Valbuena D, Landeras J, Ballesteros A, Martinez J, Mendoza S, Norman RJ, Robertson SA \& Simon C 2000 The effect of intercourse on pregnancy rates during assisted human reproduction. Human Reproduction 15 2653-2658. (doi:10.1093/humrep/15.12.2653)

Tribulo P, Bogle O, Mapletoft RJ \& Adams GP 2015 Bioactivity of ovulation inducing factor (or nerve growth factor) in bovine seminal plasma and its effects on ovarian function in cattle. Theriogenology 83 1394-1401. (doi:10.1016/j.theriogenology.2014.12.014)
Troedsson MH, Loset K, Alghamdi AM, Dahms B \& Crabo BG 2001 Interaction between equine semen and the endometrium: the inflammatory response to semen. Animal Reproduction Science 68 273-278. (doi:10.1016/S0378-4320(01)00164-6)

van Meer G, Voelker DR \& Feigenson GW 2008 Membrane lipids: where they are and how they behave. Nature Reviews. Molecular Cell Biology 9 112-124. (doi:10.1038/nrm2330)

Vasconcelos JL, Demetrio DG, Santos RM, Chiari JR, Rodrigues CA \& Sa Filho OG 2006 Factors potentially affecting fertility of lactating dairy cow recipients. Theriogenology 65 192-200. (doi:10.1016/j. theriogenology.2005.09.030)

Vasconcelos JL, Jardina DT, Sa Filho OG, Aragon FL \& Veras MB 2011 Comparison of progesterone-based protocols with gonadotropinreleasing hormone or estradiol benzoate for timed artificial insemination or embryo transfer in lactating dairy cows. Theriogenology 75 1153-1160. (doi:10.1016/j.theriogenology.2010.11.027)

Wang JX, Norman RJ \& Kristiansson P 2002 The effect of various infertility treatments on the risk of preterm birth. Human Reproduction 17 945-949. (doi:10.1093/humrep/17.4.945)

Wiltbank MC, Baez GM, Garcia-Guerra A, Toledo MZ, Monteiro PL, Melo LF, Ochoa JC, Santos JE \& Sartori R 2016 Pivotal periods for pregnancy loss during the first trimester of gestation in lactating dairy cows. Theriogenology 86 239-253. (doi:10.1016/j. theriogenology.2016.04.037)

Wood PL, Scoggin K, Ball BA, Troedsson MH \& Squires EL 2016 Lipidomics of equine sperm and seminal plasma: identification of amphiphilic (O-acyl)-omega-hydroxy-fatty acids. Theriogenology 86 1212-1221. (doi:10.1016/j.theriogenology.2016.04.012)

Ziebe S, Loft A, Povlsen BB, Erb K, Agerholm I, Aasted M, Gabrielsen A, Hnida C, Zobel DP, Munding B et al. 2013 A randomized clinical trial to evaluate the effect of granulocyte-macrophage colonystimulating factor (GM-CSF) in embryo culture medium for in vitro fertilization. Fertility and Sterility 99 1600-1609. (doi:10.1016/j. fertnstert.2012.12.043)

Received 10 June 2016

First decision 1 August 2016

Revised manuscript received 31 August 2016

Accepted 5 September 2016 